\title{
Zoneamento agroclimático de amendoinzeiro para a Bacia do Alto Paraguai (MT) ${ }^{1}$
}

\author{
João Danilo Barbieri², Rivanildo Dallacort ${ }^{2}$, \\ Adalberto Santi ${ }^{2}$, Ronicely Pereira Rocha ${ }^{2}$, Marco Antônio Camillo de Carvalho²
}

\begin{abstract}
Agroclimatic zoning of peanut plants for the Bacia do Alto Paraguai, Mato Grosso State, Brazil

The success of a technified, productive and sustainable agriculture is achieved through the knowledge on climate and soil of a place, combined with their appropriate management. This study aimed to determine the agroclimatic zoning of peanut plants for the Bacia do Alto Paraguai, Mato Grosso State, Brazil, by identifying the cities with aptitude for exploring this crop and establishing the times for its sowing. Soil and climate conditions were evaluated for the region, respecting the cycle (90-120 days) and water demands (400-600 $\mathrm{mm}$ ) of the crop. The water storage capacity (WSC) and water requirement satisfaction index (WRSI) were determined for the types of soil classified according to the clay content. It was possible to conclude that all cities that cultivate peanut plants have more than $50 \%$ of WSC 75 soil type with more than $35 \%$ of clay (Arenápolis, Barra do Bugres, Indiavaí, Lambarí D’Oeste, Nova Olímpia, Rondonópolis, São José dos Quatro Marcos and Tangará da Serra). Such soil favors a late cultivation, which can be performed up to the $7^{\text {th }}$ ten-days period. For the WSC 30 soil type, with less than $15 \%$ of clay, the cultivation should only start from the $6^{\text {th }}$ ten-days period, due to its low water absorption capacity.
\end{abstract}

KEY-WORDS: Arachis hipogea L.; ordinary kriging; climate risk.

\section{INTRODUÇÃO}

O amendoim (Arachis hypogea L.) é uma espécie dicotiledônea, herbácea e anual, pertencente à família Fabaceae. Segundo o Registro Nacional de Cultivares (Brasil 2013), existem, atualmente, vinte e seis cultivares registradas da espécie $A$. hypogaea, que se destinam, prioritariamente, à comercialização de sementes no País.

A produção mundial de amendoim encontra-se na faixa de 33,2 milhões de toneladas de grãos, sendo $30 \%$ dessa produção destinada ao consumo huma-

\section{RESUMO}

O sucesso de uma agricultura tecnificada, produtiva e sustentável é obtido por meio do conhecimento do clima e solo da localidade, combinado com o seu adequado manejo. Este estudo objetivou determinar o zoneamento agroclimático da cultura do amendoim para a região da Bacia do Alto Paraguai, no Estado de Mato Grosso, identificando os municípios que apresentam aptidão para a exploração dessa cultura e estabelecendo as épocas para a sua semeadura. Foram analisadas as condições edafoclimáticas da região, respeitando-se o ciclo (90-120 dias) e as exigências hídricas (400-600 mm) da cultura. Para os tipos de solos classificados de acordo com o teor de argila, foram determinados a capacidade de armazenamento de água (CAD) e o índice de satisfação e necessidade de água (ISNA). Concluiuse que todos os municípios que cultivam amendoim apresentam mais que $50 \%$ de solo tipo CAD 75, com mais de $35 \%$ de argila (Arenápolis, Barra do Bugres, Indiavaí, Lambarí D’Oeste, Nova Olímpia, Rondonópolis, São José dos Quatro Marcos e Tangará da Serra). Esse tipo de solo favorece o cultivo tardio, que pode ser realizado até o $7^{\circ}$ decêndio. Já para os solos tipo CAD 30, com menos de $15 \%$ de argila, o cultivo só deve se iniciar a partir do $6^{\circ}$ decêndio, por apresentarem baixa capacidade de absorção de água.

PALAVRAS-CHAVE: Arachis hipogea L.; krigagem ordinária; risco climático.

no, tanto na forma in natura como industrializada. Os 70 \% restantes são utilizados para a produção de óleo comestível.

A produção do amendoim brasileiro é oriunda, em maior escala, da região Sudeste, seguida pelas regiões Centro-Oeste e Nordeste (Embrapa 2013), com total de 110 mil ha de área plantada e produção de 340 mil toneladas (Conab 2015).

O Estado de Mato Grosso possui área de $903.357,91 \mathrm{~km}^{2}$, 141 municípios, 25 microrregiões (Mato Grosso 2010) e limites com a Bolívia e os Estados do Pará, Amazonas, Tocantins, Goiás, Mato 
Grosso do Sul e Rondônia. A Amazônia (53,6 \%), o Cerrado (39,6 \%) e o Pantanal (6,8 \%) são os biomas que compõem o Estado.

Segundo Cunha \& Assad (2001), os fatores climáticos são os principais causadores de flutuações no rendimento de grãos das culturas, pois temperatura e precipitação, por exemplo, não podem ser controladas ou modificadas pelo homem, em grande escala.

O amendoim é cultivado nos dois hemisférios, principalmente em regiões tropicais, na faixa de latitude $30^{\circ} \mathrm{N}$ e S (Silva \& Beltrão 2000). Apesar dessa ampla adaptabilidade, sua produtividade é fortemente influenciada por fatores ambientais, que podem reduzir, drasticamente, o crescimento da planta, dependendo do estádio em que essa se encontra (vegetativo ou reprodutivo).

O sucesso de uma agricultura tecnificada, produtiva e sustentável é obtido por meio do conhecimento do clima e solo da localidade, combinado ao seu manejo adequado. O mapeamento edafoclimático de uma região permite a seleção de condições mais adequadas à implantação das culturas. Uma cultura só pode ser considerada apta para uma região se ali forem atendidas suas necessidades climáticas, durante todo o seu ciclo (Pereira et al. 2002).

Segundo Silva \& Beltrão (2000), as condições que impossibilitam o armazenamento de água no solo são fatores que ocasionam o déficit hídrico. Esses fatores são constantes nas atividades agrícolas, durante a maior parte do ano. Portanto, o conhecimento das

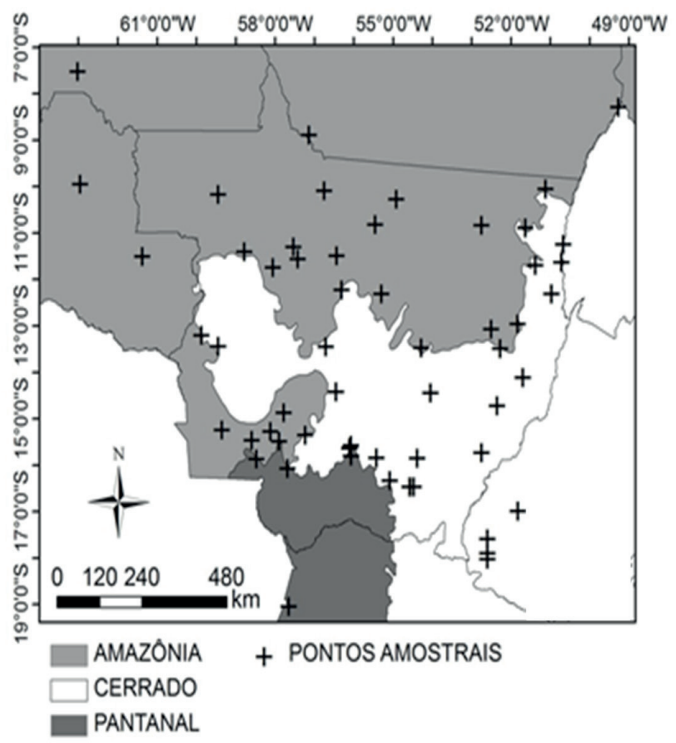

Figura 1. Distribuição espacial das estações meteorológicas e postos pluviométricos utilizados. características ambientais de uma região é prática imprescindível para o zoneamento dos sítios que proporcionam o melhor desenvolvimento de uma determinada cultura.

Este estudo objetivou determinar o zoneamento agroclimático da cultura do amendoim para a região da Bacia do Alto Paraguai, no Estado de Mato Grosso (região sul de MT), observando-se as variabilidades climáticas presentes dentro da região e determinando-se as áreas e os períodos favoráveis ao desenvolvimento dessa atividade agrícola.

\section{MATERIAL E MÉTODOS}

Foram utilizados dados edafoclimáticos da região da Bacia do Alto Paraguai (BAP) para a realização dos cálculos de índice de satisfação de necessidade de água (ISNA) e, posteriormente, classificou-se a aptidão da cultura para a região.

Para contemplar os objetivos propostos, foram utilizados dados decendiais de temperatura e precipitação pluviométrica de 38 estações meteorológicas, localizadas no Estado de Mato Grosso e em regiões próximas ao Estado, para que fosse possível a interpolação e análise de dados para a Bacia do Alto Paraguai (Figuras 1 e 2). Os dados são provenientes de estações do Instituto Nacional de Meteorologia (Inmet), Centro de Previsão do Tempo e Estudos Climáticos (CPTEC) e Secretaria de Estado e Desenvolvimento Ambiental (Sedam), disponibilizados

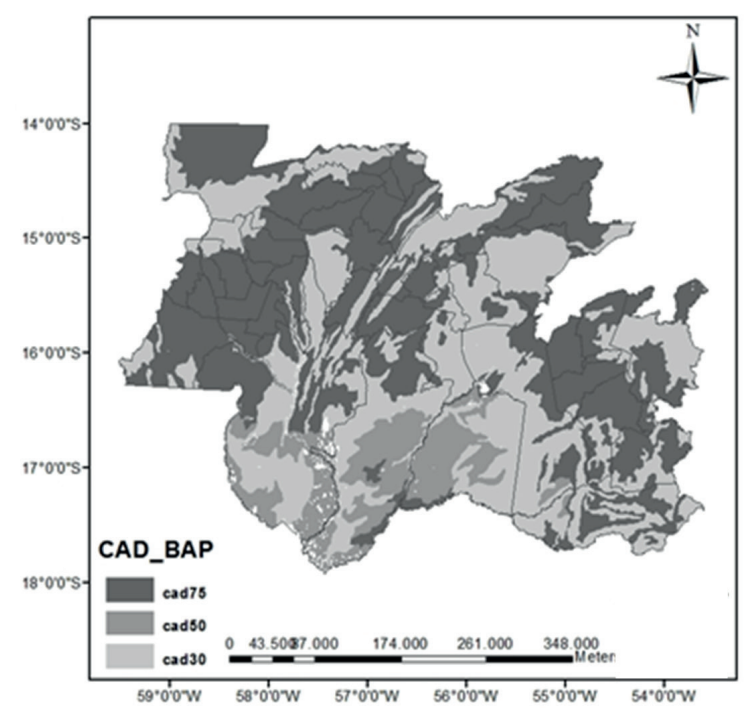

Figura 2. Representação das classes de capacidade de água disponível para os municípios da região da Bacia do Alto Paraguai (MT) (adaptado de Sans et al. 2001). 
pelo site Agritempo, sendo, também, apresentados no banco de dados da Empresa Brasileira de Pesquisa Agropecuária (Embrapa 2013), com os 12 últimos anos de observação.

Para a tabulação e análise dos dados, utilizou-se o programa CLIMA (Faria et al. 2003), para determinação do índice de satisfação de necessidade de água (ISNA), de acordo com metodologia adaptada de Rolim et al. (1998). A estimativa do ISNA foi feita para cada época de semeadura do decêndio 1 ao 10 , período que apresenta variabilidade nos semivariogramas. Os índices gerados foram classificados conforme metodologia proposta por Farias et al. (2001), em que: Inapto $=$ ISNA $<0,55 ;$ Restrito $=0,55<$ ISNA $<0,65 ;$ e Apto $=$ ISNA $>0,65$, comparados com o estádio crítico da cultura (floração/enchimento de grão), para cada época de semeadura. Os valores de ISNA foram determinados para as três capacidades de água $(30 \mathrm{~mm}, 50 \mathrm{~mm}$ e $75 \mathrm{~mm})$ disponível nos solos da Bacia do Alto Paraguai.

Em seguida, os semivariograms foram ajustados para cada época e selecionaram-se os modelos que apresentaram os melhores ajustes, tendo-se como um dos parâmetros o grau de dependência espacial (GDE), classificado de acordo com Dalchiavon et al. (2012): GDE $<20 \%$ - muito baixa dependência espacial; $20 \%<\mathrm{GDE}<40 \%$ - baixa dependência; $40 \%<$ GDE $<60 \%$ - dependência média; $60 \%<$ GDE $<80 \%$ - alta dependência; e $80 \%<$ GDE $<$ $100 \%$ - muito alta dependência.

Após a interpolação dos dados e ajustes dos semivariogramas, foram determinadas 5 épocas de semeadura (em decêndios), que perfazem o período de transição entre a última época completamente apta e a primeira completamente inapta ao cultivo. Esse período foi determinado por meio do INSA e corresponde aos decêndios 6 (21/02 a 28/02), 7 (01/03 a $10 / 03), 8(11 / 03$ a $20 / 03), 9(21 / 03$ a $31 / 03)$ e 10 (01/04 a 10/04).

Posteriormente, os dados e os índices foram inseridos em ambiente SIG e, de acordo com os coeficientes determinados nos ajustes de semivariogramas, realizou-se krigagem ordinária. Em seguida, foram gerados mapas com as classes de aptidão, de acordo com as classes de solo e respectivas CAD (Sans et al. 2001).

A BAP apresenta área total de, aproximadamente, $363.442 \mathrm{~km}^{2}$, em território nacional, e de $172.096 \mathrm{~km}^{2}$, no Estado de Mato Grosso. Nessa região, existem áreas com restrição à atividade agrí- cola, como reservas legais e áreas de alagamento, indígenas e urbanas, as quais foram consideradas como de cultivo restrito no zoneamento.

O zoneamento foi realizado em área total de, aproximadamente, $55.451 \mathrm{~km}^{2}$, o que representa cerca de $32 \%$ da Bacia do Alto Paraguai localizada no Estado de Mato Grosso, nos municípios de Barão de Melgaço (100\% de área alagável), Cáceres (59 \%), Curvelândia (29\%), Itiquira (42\%), Lambari D'Oeste (3\%), Nossa Senhora do Livramento (21 \%), Poconé (83\%), Porto Estrela (3\%), Rondonópolis (19\%) e Santo Antônio do Leverger (77\%).

\section{RESULTADOS E DISCUSSÃO}

Dos 44 municípios avaliados na Bacia do Alto Paraguai, 31 apresentam mais de $50 \%$ de seu território com solo de capacidade de água disponível (CAD) de $75 \mathrm{~mm}$. Somente 8 municípios apresentam solo com CAD de $50 \mathrm{~mm}$, sendo estes localizados em área de alagamento que deve ser preservada, impossibilitando a ação agrícola.

Solos com alto conteúdo de argila e silte retêm mais água disponível que solos com alto conteúdo de areia. Em solos arenosos, os mecanismos de retenção de água, seja por capilaridade ou adsorção, são menos eficientes (Gonçalves et al. 2011).

Os valores de ISNA encontrados para as diferentes CAD apresentam comportamento semelhante, no decorrer dos decêndios. O desvio padrão dos valores de ISNA é menor nos primeiros decêndios $\left(1^{\circ}\right.$ ao $5^{\circ}$ ), devido à maior precipitação incidente durante esse período (Tabela 1). Já para os últimos decêndios $\left(6^{\circ}\right.$ ao $\left.10^{\circ}\right)$, o índice de precipitação é menor e o desvio padrão é maior.

A estação seca ocorre devido ao movimento de massas de ar atuantes sobre o Estado, o que causa maior variabilidade das médias pluviométricas, provocando maior aleatoriedade nos dados e aumentando, consequentemente, o desvio (Dalchiavon et al. 2012). Segundo Martins et al. (2011), a BAP apresenta características intrínsecas de vegetação e relevo que aumentam a variabilidade e distribuição da precipitação no Estado.

Observou-se que os valores de ISNA, para a CAD de $30 \mathrm{~mm}$, vão do primeiro ao quinto decêndio, apresentando médias próximas ou acima de 0,90 e desvio padrão abaixo de 0,13 . Dessa forma, os cinco primeiros decêndios são todos aptos para o plantio de amendoinzeiro na região da BAP, não apresentando 
Tabela 1. Valores médios de índice de satisfação de necessidade de água (ISNA) e desvio padrão (DP) para as capacidades de água disponível no solo de $30 \mathrm{~mm}, 50 \mathrm{~mm}$ e $75 \mathrm{~mm}$, do decêndio 1 ao 10, para o Estado de Mato Grosso.

\begin{tabular}{ccccccc}
\hline \multirow{2}{*}{ Decêndio } & \multicolumn{2}{c}{ ISNA de $30 \mathrm{~mm}$} & \multicolumn{2}{c}{ ISNA de $50 \mathrm{~mm}$} & \multicolumn{2}{c}{ ISNA de $75 \mathrm{~mm}$} \\
\cline { 2 - 6 } & Média & DP & Média & DP & Média & DP \\
\hline 1 & 0,9945 & 0,0176 & 0,9961 & 0,0120 & 0,9974 & 0,0091 \\
2 & 0,9868 & 0,0354 & 0,9908 & 0,0249 & 0,9947 & 0,0180 \\
3 & 0,9776 & 0,0503 & 0,9826 & 0,0421 & 0,9897 & 0,0280 \\
4 & 0,9524 & 0,0785 & 0,9611 & 0,0663 & 0,9718 & 0,0469 \\
5 & 0,8938 & 0,1212 & 0,9124 & 0,1032 & 0,9308 & 0,0841 \\
6 & 0,7961 & 0,1556 & 0,8255 & 0,1412 & 0,8550 & 0,1194 \\
7 & 0,6762 & 0,1843 & 0,7203 & 0,1708 & 0,7568 & 0,1592 \\
8 & 0,5624 & 0,2066 & 0,6189 & 0,1836 & 0,6461 & 0,1648 \\
9 & 0,4359 & 0,2147 & 0,5334 & 0,1714 & 0,5650 & 0,1617 \\
10 & 0,3239 & 0,1989 & 0,4492 & 0,1610 & 0,4822 & 0,1549 \\
\hline
\end{tabular}

variabilidade espacial para as diferentes classes de solo (CAD de $30 \mathrm{~mm}, 50 \mathrm{~mm}$ e $75 \mathrm{~mm}$ ).

Para a CAD de $50 \mathrm{~mm}$, as médias dos valores de ISNA, no sexto decêndio, chegaram a 0,82 , contra os 0,85 para a CAD de $75 \mathrm{~mm}$, e o desvio padrão chegou a 0,11 . A partir do décimo decêndio, o desvio padrão aumentou, o que impossibilitou o ajuste de semivariogramas e, consequentemente, a krigagem, para a geração dos mapas de aptidão. Resultados similares foram obtidos por Xavier et al. (2010), que avaliaram o método de krigagem ordinária na interpolação de dados.

Dessa forma, define-se como apta a semeadura do amendoim em toda a BAP, nos decêndios de 1 a 7 , para a CAD de $30 \mathrm{~mm}$ e de $50 \mathrm{~mm}$, e de 1 a 8 , para a CAD de $75 \mathrm{~mm}$. Na Tabela 2, estão apresentados os dados a partir do decêndio 6, pela impossibilidade do ajuste de semivariogramas e, consequentemente, krigagem, para a geração dos mapas de aptidão.

Segundo classificação proposta por Dalchiavon et al. (2012), na CAD de $30 \mathrm{~mm}$, as épocas 7 , 8,9 e 10 apresentaram alta dependência espacial (Tabela 2). A época 6 foi a única com média de erro quadrático médio (RMSE) para dependência espacial abaixo de 0,15 . Para a CAD de $50 \mathrm{~mm}$, o grau de dependência espacial apresenta valores médios para todas as épocas e o RMSE médio foi de 0,149 . Por fim, na CAD de $75 \mathrm{~mm}$, a época 7 apresentou baixa dependência espacial, enquanto as demais épocas (6, 8,9 e 10) apresentaram média dependência espacial e RMSE médio de 0,137.

Os menores valores de RMSE foram observados na CAD de $75 \mathrm{~mm}$. Isso se deve ao menor desvio dos dados, o que é representado também no GDE dos semivariogramas ajustados. Xavier et al. (2010) verificaram que quanto menor for o RMSE, melhor será o ajuste dos dados ao modelo interpolador, possibilitando, dessa forma, a interpolação desses dados por krigagem ordinária.

Na Tabela 3, são apresentados os modelos ajustados, número de pares no primeiro Lag e seus coeficientes: efeito pepita, patamar, alcance e grau de dependência espacial (GDE). Foram ajustados semivariogramas apenas para as épocas em que houve dependência espacial (decêndios 6 a 10), ou seja, épocas em que não houve o efeito pepita puro. As épocas com efeito pepita puro são aquelas em que a amostragem atual não representa significativamente a área amostrada, não sendo possível a realização de krigagem, por não haver continuidade espacial.

Os modelos ajustados para os valores de ISNA da CAD de $30 \mathrm{~mm}$, no Estado de Mato Grosso, são apresentados nas Figura 3A, 3B, 3C, 3D e 3E, respectivamente para os decêndios $6,7,8,9$ e 10 .

Tabela 2. Grau de dependência espacial (GDE), segundo Dalchiavon et al. (2012), e erro quadrático médio (RMSE) para as capacidades de água disponível (CAD) de $30 \mathrm{~mm}, 50 \mathrm{~mm}$ e $75 \mathrm{~mm}$, para o Estado de Mato Grosso.

\begin{tabular}{|c|c|c|c|c|c|c|}
\hline \multirow{2}{*}{ Decêndio } & \multicolumn{2}{|c|}{ CAD de $30 \mathrm{~mm}$} & \multicolumn{2}{|c|}{ CAD de $50 \mathrm{~mm}$} & \multicolumn{2}{|c|}{ CAD de $75 \mathrm{~mm}$} \\
\hline & GDE & RMSE & GDE & RMSE & GDE & RMSE \\
\hline 6 & 57,143 & 0,144 & 53,846 & 0,128 & 52,426 & 0,111 \\
\hline 7 & 63,303 & 0,167 & 57,108 & 0,153 & 39,362 & 0,146 \\
\hline 8 & 70,403 & 0,167 & 50,427 & 0,167 & 53,448 & 0,151 \\
\hline 9 & 60,633 & 0,185 & 44,522 & 0,157 & 51,089 & 0,144 \\
\hline 10 & 63,113 & 0,158 & 44,792 & 0,144 & 55,752 & 0,137 \\
\hline
\end{tabular}


Tabela 3. Descrição de resultados dos semivariogramas ajustados com o programa Variowin.

\begin{tabular}{|c|c|c|c|c|c|}
\hline Decêndio & 6 & 7 & 8 & 9 & 10 \\
\hline \multicolumn{6}{|c|}{$C A D$ de $30 \mathrm{~mm}$} \\
\hline Modelo & Exponencial & Esférico & Esférico & Esférico & Exponencial \\
\hline Pares de Lag & 106 & 106 & 104 & 102 & 100 \\
\hline Efeito Pepita & 0,0125 & 0,016 & 0,0169 & 0,0224 & 0,018 \\
\hline Patamar & 0,0293 & 0,0436 & 0,0571 & 0,0569 & 0,0487 \\
\hline Alcance & $1.066,000$ & $1.230,000$ & $1.162,000$ & $1.161,950$ & $1.400,000$ \\
\hline GDE & 57,14 & 63,3 & 70,4 & 60,63 & 63,11 \\
\hline \multicolumn{6}{|c|}{$C A D$ de $50 \mathrm{~mm}$} \\
\hline Modelo & Exponencial & Gaussiano & Gaussiano & Gaussiano & Exponencial \\
\hline Pares de Lag & 72 & 122 & 102 & 102 & 102 \\
\hline Efeito Pepita & 0,0108 & 0,0193 & 0,0232 & 0,0198 & 0,0159 \\
\hline Patamar & 0,0234 & 0,045 & 0,0468 & 0,0356 & 0,0288 \\
\hline Alcance & $1.200,000$ & $1.200,000$ & $1.500,000$ & $1.110,000$ & $1.050,000$ \\
\hline GDE & 53,84 & 57,1 & 50,42 & 44,52 & 44,79 \\
\hline \multicolumn{6}{|c|}{$C A D$ de $75 \mathrm{~mm}$} \\
\hline Modelo & Esférico & Esférico & Gaussiano & Esférico & Gaussiano \\
\hline Pares de Lag & 76 & 118 & 80 & 102 & 102 \\
\hline Efeito Pepita & 0,0078 & 0,0171 & 0,0162 & 0,0155 & 0,0150 \\
\hline Patamar & 0,0164 & 0,0282 & 0,0348 & 0,0316 & 0,0339 \\
\hline Alcance & 756,000 & $1.500,000$ & $1.500,000$ & $1.305,000$ & $1.500,000$ \\
\hline GDE & 52,42 & 39,36 & 53,44 & 51,08 & 55,75 \\
\hline
\end{tabular}
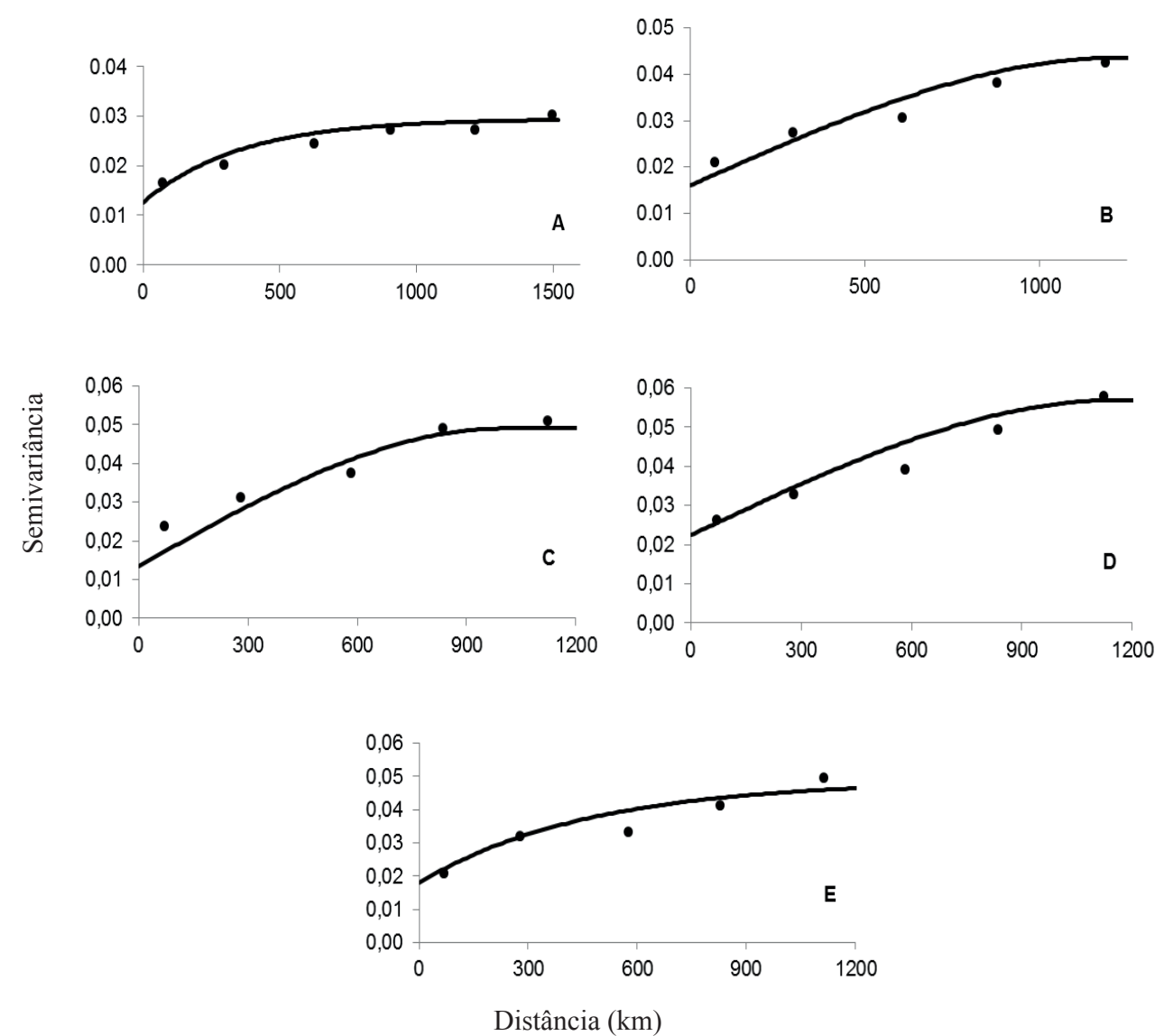

Figura 3. Semivariogramas experimentais ajustados aos índices de satisfação de necessidade de água (ISNA), para as épocas de semeadura do amendoim 6 (A), 7 (B), 8 (C), 9 (D) e 10 (E), no Estado de Mato Grosso, para a CAD de 30 mm. 
Com base na classificação de Dalchiavon et al. (2012), os solos com CAD de $50 \mathrm{~mm}$ apresentam médio grau de dependência espacial para todas as épocas (Tabela 3). Os dados dos semivariogramas do ISNA desses solos são representados na Figura 4.

Na Figura 5, estão apresentados os semivariogramas ajustados para solos com CAD de $75 \mathrm{~mm}$, sendo que as épocas de semeadura anteriores à época 6 apresentaram efeito pepita puro, não havendo condições de interpolação dos dados.

$\mathrm{O}$ efeito pepita $\left(\mathrm{C}_{0}\right)$ é uma forma de representação de variância não explicada pela escala espacial em que a amostragem foi realizada (Corá et al. 2004, Lemos Filho et al. 2008, Schaffrath et al. 2008). Diante disso, a rede de estações utilizadas não é suficiente para detectar variabilidade na BAP, considerando-se a CAD de $75 \mathrm{~mm}$ para os valores de ISNA, não sendo possível a interpolação dos dados pelo método de krigagem.

Para a CAD de $75 \mathrm{~mm}$, em todas as épocas, os dados apresentam média dependência espacial do $6^{\circ}$ ao $10^{\circ}$ decêndio, com exceção da época de semeadura 7 (Tabela 3). Esses resultados corroboram o estudo de Dalchiavon et al. (2012), em que a dependência espacial entre as estações diminui com a maior incidência de chuvas, devido à maior similaridade entre os dados obtidos durante a estação chuvosa.

Devido à falta de estações meteorológicas na região da $\mathrm{BAP}$, os dados de temperatura e precipitação iniciais utilizados para o cálculo do ISNA apresentaram grande variabilidade espacial, pois a pesquisa abrangeu todo o Estado de Mato Grosso. Como esse Estado possui grande heterogeneidade edafoclimática, caracterizada pela existência de três biomas em sua área, os semivariogramas construídos apresentaram valores de GDE satisfatórios, variando de médios a altos.

Resultados semelhantes foram obtidos por Ávilla et al. (2009), que, trabalhando com o mapeamento da precipitação mínima provável para o Estado de Minas Gerais, encontraram valores de GDE entre $52 \%$ e $79 \%$, para a precipitação mensal
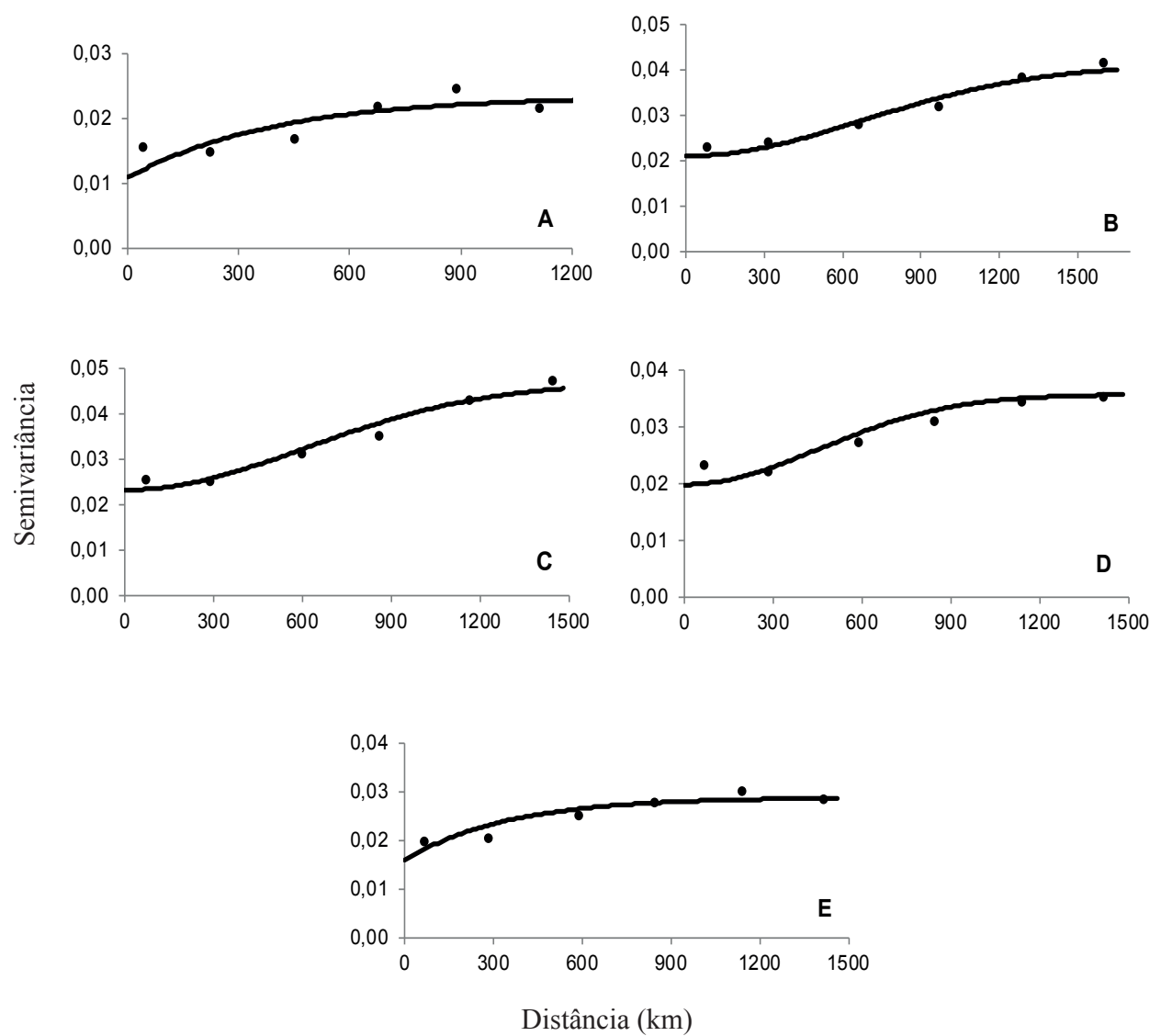

Figura 4. Semivariogramas experimentais ajustados aos índices de satisfação de necessidade de água (ISNA), para as épocas de semeadura do amendoim 6 (A), 7 (B), 8 (C), 9 (D) e 10 (E), no Estado de Mato Grosso, para a CAD de 50 mm. 

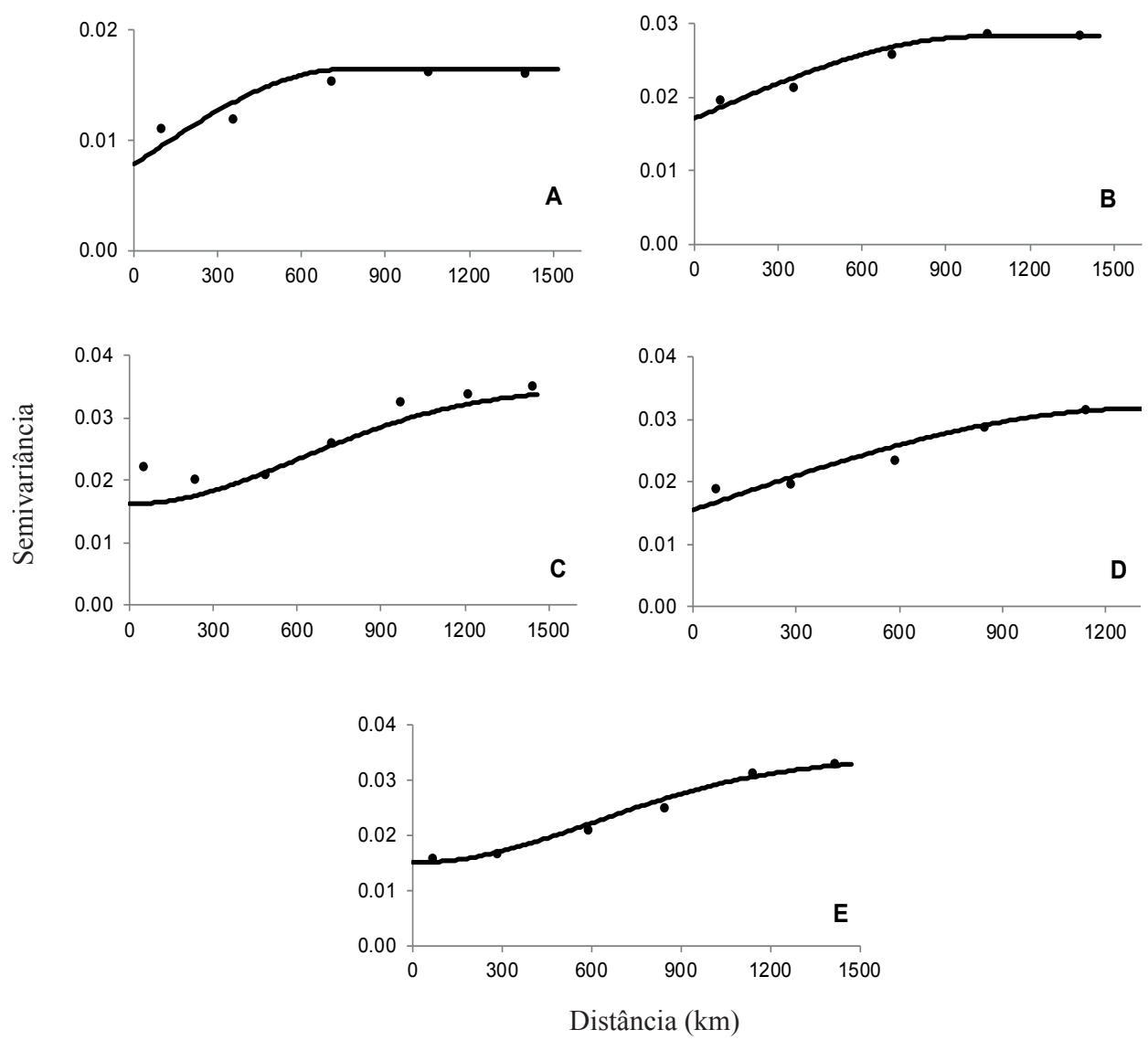

Figura 5. Semivariogramas experimentais ajustados aos índices de satisfação de necessidade de água (ISNA), para as épocas de semeadura do amendoim 6 (A), 7 (B), 8 (C), 9 (D) e 10 (E), no Estado de Mato Grosso, para a CAD de 75 mm.

do Estado, nos meses de outubro a março. Assad et al. (2003), avaliando os métodos de espacialização de índices agrometeorológicos, concluíram que os métodos geoestatísticos podem ser usados na espacialização do ISNA. Neste estudo, os modelos de melhor ajuste foram o esférico, na maioria dos casos, e o exponencial.

Na Figura 6, estão apresentados os mapas de zoneamento do amendoim, para as épocas de semeadura do decêndio 6 ao 10. Para as épocas de semeadura do decêndio 1 ao 5, não houve variabilidade espacial para os valores de ISNA, sendo, assim, consideradas aptas (ISNA $>0,65$ ) para toda a BAP, em solos com CAD de $30 \mathrm{~mm}, 50 \mathrm{~mm}$ e $75 \mathrm{~mm}$. O inverso ocorre para os decêndios de 10 em diante, que caracterizam o período seco na região, em que o cultivo do amendoinzeiro se torna inapto (ISNA $<0,55$ ) para toda a BAP, nos solos com CAD de $30 \mathrm{~mm}$, $50 \mathrm{~mm}$ e $75 \mathrm{~mm}$.

Considerando-se que a semeadura do amendoim se inicia no primeiro decêndio, nota-se que a semeadura realizada no decêndio 6 (época 6) apresenta $100 \%$ da área agricultável apta ao cultivo, para todos os municípios (Figura 6). Já para o decêndio 10 (época 10), $100 \%$ da área da BAP é classificada como inapta para o cultivo de amendoim. Assim, os decêndios 6 a 10 marcam o período de transição entre as épocas aptas e inaptas.

A semeadura realizada no decêndio 7 (época 7) apresenta restrições apenas nos solos classificados com CAD de $30 \mathrm{~mm}$. A baixa capacidade de armazenamento de água e o início da estação seca, que principia na região nordeste e segue para o sudoeste da BAP, restringem o crescimento das culturas agrícolas (Silva \& Beltrão 2000, Martins et al. 2011). Nessa época, as regiões com CAD de $75 \mathrm{~mm}$ estão aptas ao cultivo do amendoim.

$\mathrm{Na}$ época 8 , há aumento significativo da restrição, seguindo do nordeste para o sudoeste da BAP, tornando possível o cultivo apenas nos municípios de Tangará da Serra (26\% de sua extensão), Barra do Bugres (27\%), Araputanga (100 \%), Figueirópolis 

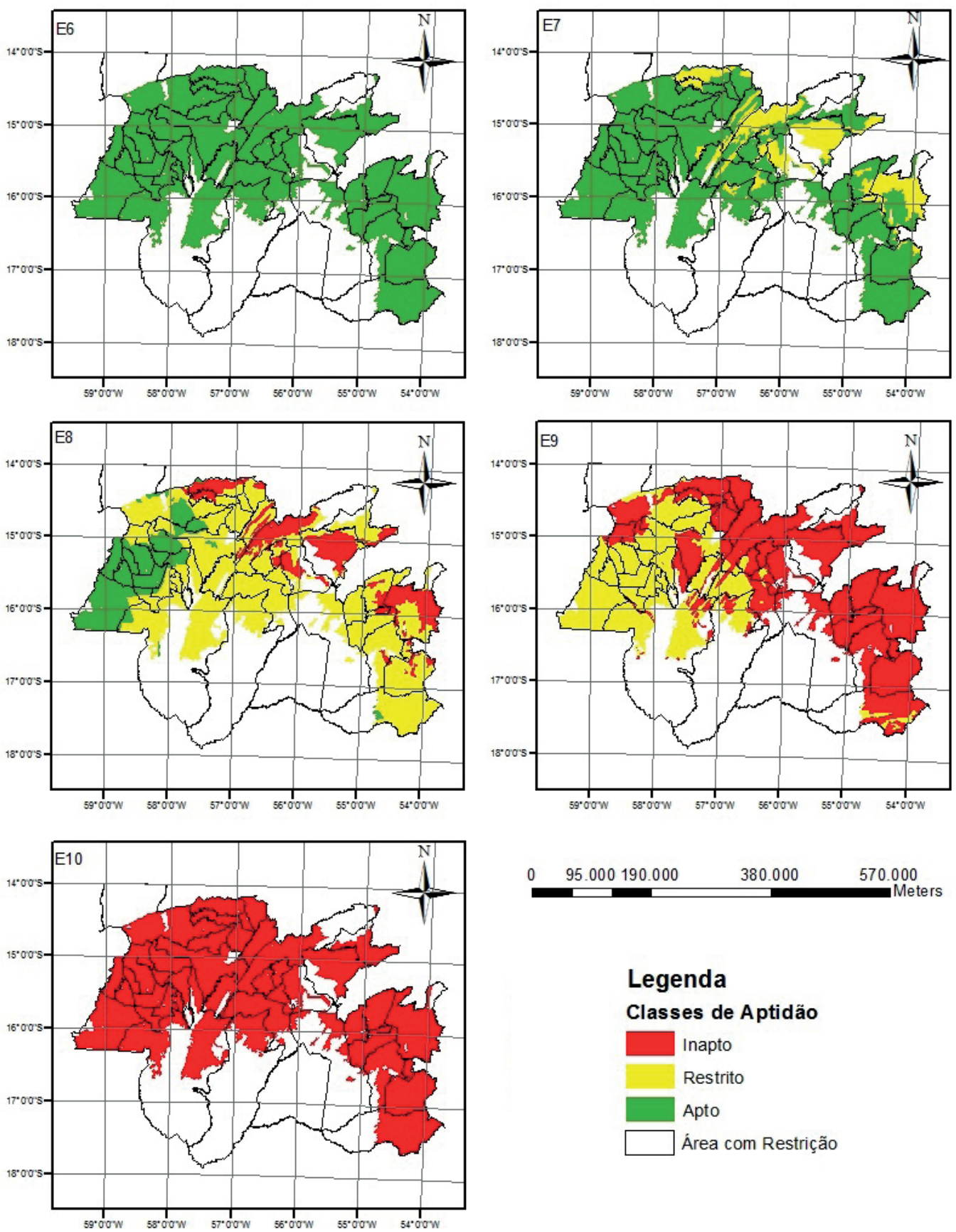

Legenda
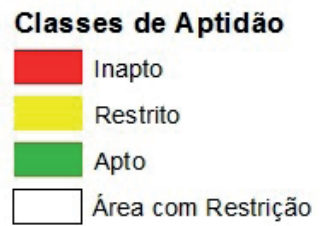

Figura 6. Zoneamento edafoclimático e classes de risco de semeadura do amendoim, para as épocas de semeadura 6 (E6), 7 (E7), 8 (E8), 9 (E9) e 10 (E10), na Bacia do Alto Paraguai (MT), para as classes de ISNA.

(100\%), Indiavaí (100\%), Jaurú (100\%), Lambari (53\%), Nova Olímpia (37\%), Porto Esperidião (100\%), Rio Branco (100\%), Salto do Céu (87\%) e São José dos Quatro Marcos (100\%). Essas regiões apresentam CAD de $75 \mathrm{~mm}$ em $94 \%$ da área total. Isso implica em maior armazenamento de água no solo, possibilitando o cultivo tardio. Para essa época, somente o município de Porto Esperidião apresenta área de $973 \mathrm{~km}^{2}$ apta ao cultivo de amendoim, para solo tipo CAD de $30 \mathrm{~mm}$.

Souza Filho \& Gomes (2007), em estudo com diferentes classes de CAD, observaram que o solo com maior capacidade de armazenamento de água suporta maior período de escassez hídrica.

Para a época 9, todos os municípios que apresentam solo classificado como CAD de $30 \mathrm{~mm}$ são 
inaptos ao cultivo. Os solos com CAD de $75 \mathrm{~mm}$, nos municípios a oeste da BAP, são todos de cultivo restrito. Com a possibilidade de restrição hídrica à cultura, é necessária a utilização de sistema de irrigação.

Dallacort et al. (2011) concluíram que a distribuição da precipitação no Estado de Mato Grosso não apresenta uniformidade para todos os municípios, fazendo-se necessária a utilização de irrigação.

O comportamento dos valores de ISNA, nas diferentes épocas de semeadura e CAD do solo, assemelha-se muito ao deslocamento das massas de ar que ocorrem no Estado. Os valores de ISNA acompanham o regime pluviométrico, com sentido de deslocamento do nordeste ao sudoeste. O aumento da disponibilidade de água no solo promove, consequentemente, aumento nos valores de ISNA, favorecendo o cultivo em épocas mais tardias.

Para a época 9, os municípios com restrição apresentam solos com CAD de $75 \mathrm{~mm}$, restringindo o cultivo em Araputanga (100 \%), Barra do Bugres $(85 \%)$, Cáceres (47\%), Curvelândia (97\%), Figueirópolis (100\%), Glória do Oeste (100\%), Indiavaí (100\%), Itiquira (26\%), Jangada (27\%), Jaurú (100\%), Lambari do Oeste (100\%), Mirassol (100\%), Nossa Senhora do Livramento (65\%), Nova Marilândia (34\%), Nova Olímpia (92\%), Poconé (17\%), Porto Esperidião (100\%), Porto Estrela (83\%), Reserva do Cabaçal (100\%), Rio Branco (100\%), Rosário Oeste (6\%), Salto do Céu (100\%), Santo Afonso (68\%), São José dos Quatro Marcos (100 \%), Tangará da Serra (49\%) e Várzea Grande (64\%). O restante das áreas e dos municípios é classificado como inapto ao cultivo do amendoim, para essa época.

\section{CONCLUSÕES}

1. Considerando-se os índices de satisfação de necessidade hídrica, a região da Bacia do Alto Paraguai do Estado do Mato Grosso é apta para o cultivo de amendoim com semeadura realizada do decêndio 1 ao $6(01 / 01$ a 10/02).

2. Levando-se em consideração somente os decêndios que apresentaram variabilidade espacial $\left(6^{\circ}\right.$ ao $10^{\circ}$ ), para solos com CAD de $30 \mathrm{~mm}$, a aptidão é considerada restrita, quando a semeadura ocorre a partir do decêndio 7, chegando ao decêndio 8 com $97 \%$ da área total inapta ou restrita.
3. Para solos com CAD de $75 \mathrm{~mm}$, a classe de aptidão se estende para o decêndio 8, apresentando $100 \%$ da área total dos municípios de Araputanga, Figueirópolis do Oeste, Indiavaí, Jaurú, Porto Esperidião, Rio Branco, Salto do Céu e São José dos Quatro Marcos aptos ao cultivo do amendoinzeiro.

\section{REFERÊNCIAS}

ASSAD, E. D. et al. Avaliação de métodos geoestatísticos na espacialização de índices agrometeorológicos para definir riscos climáticos. Pesquisa Agropecuária Brasileira, Brasília, DF, v. 38, n. 2, p. 161-171, 2003.

ÁVilla, L. F.; Mello, C. R.; Viola, M. R. Mapeamento da precipitação mínima provável para o sul de Minas Gerais. Revista Brasileira de Engenharia Agricola e Ambiental, Campina Grande, v. 13, n. 6, p. 906915, 2009.

BRASIL. Ministério da Agricultura, Pecuária e Abastecimento. Registro nacional de cultivares. 2013. Disponível em: <http://www.agricultura.gov.br/ vegetal/registros-autorizacoes/registro/registro-nacionalcultivares>. Acesso em: 14 dez. 2013.

COMPANHIA NACIONAL DE ABASTECIMENTO (Conab). Acompanhamento da safra brasileira: grãos, sétimo levantamento, abril 2015. Brasília, DF: Conab, 2015.

CORÁ, J. E. et al. Variabilidade espacial de atributos do solo para adoção do sistema de agricultura de precisão na cultura da cana-de-açúcar. Revista Brasileira de Ciência do Solo, Viçosa, v. 28, n. 6, p. 1013-1021, 2004.

CUNHA, G. R.; ASSAD, E. D. Uma visão geral do número especial da RBA sobre zoneamento agrícola no Brasil. Revista Brasileira de Agrometeorologia, Passo Fundo, v. 9, n. 3, p. 377-385, 2001.

DALCHIAVON, F. C. et al. Variabilidade espacial de atributos da fertilidade de um Latossolo Vermelho distroférrico sob sistema plantio direto. Revista Ciência Agronômica, Fortaleza, v. 43, n. 3, p. 453-461, 2012.

DALLACORT, R. et al. Distribuição das chuvas no município de Tangará da Serra, médio norte do Estado de Mato Grosso, Brasil. Acta Scientiarum Agronomy, Maringá, v. 33, n. 2, p. 193-200, 2011.

EMPRESA BRASILEIRA DE PESQUISA AGROPECUÁRIA (Embrapa). Recomendações técnicas para o cultivo do amendoim em pequenas propriedades agricolas do Nordeste brasileiro. Campina Grande: Embrapa Algodão, 2013. (Circular técnica, 102). 
FARIA, R. T.; CHIBANA, E. Y.; CARAMORI, P. H. Programa computacional para organização e análise de dados meteorológicos. Engenharia Agrícola, Londrina, v. 23 , n. 2, p. 372-387, 2003.

FARIAS, J. R. B. et al. Caracterização de risco de déficit hídrico nas regiões produtoras de soja no Brasil. Revista Brasileira de Agrometeorologia, Santa Maria, v. 9, n. 3, p. 415-421, 2001.

GONÇALVES, A. C. A. et al. Influência da densidade do solo na estimativa do conteúdo de água de um Nitossolo Vermelho distroférrico por meio da técnica de TDR. Revista Brasileira de Ciência do Solo, Viçosa, v. 35, n. 5, p. 1551-1559, 2011.

LEMOS FILHO, L. C. A. et al. Variação espacial da densidade do solo e matéria orgânica em área cultivada com cana-de-açúcar (Saccharum officinarum L.). Revista Ciência Agronômica, Fortaleza, v. 39, n. 2, p. 193-202, 2008.

MARTINS, J. A. et al. Caracterização do regime pluviométrico no arco das nascentes do Rio Paraguai. Revista Brasileira de Meteorologia, São José dos Campos, v. 26, n. 4, p. 639-647, 2011.

MATO GROSSO. Secretaria de Estado de Meio Ambiente. Mapa dos biomas mato-grossenses. 2010. Disponível em: $<$ http://www.sema.mt.gov.br/index.php?option=com_co ntent\&view $=$ article $\& i d=170 \&$ Itemid $=107>$. Acesso em: 06 ago. 2014.

PEREIRA, A. R.; ANGELOCCI, L. R.; SENTELHAS, P. C. Agrometeorologia: fundamentos e aplicações práticas. Guaíba: Agropecuária, 2002.
ROLIM, G. S.; SENTELHAS, P. C.; BARBIERI, V. Planilhas no ambiente Excel ${ }^{\mathrm{TM}}$ para os cálculos de balanços hídricos normal, sequencial, de cultura e de produtividade real e potencial. Revista Brasileira de Agrometeorologia, Santa Maria, v. 6, n. 1, p. 133-137, 1998.

SANS, L. M. A. et al. Zoneamento de riscos climáticos para a cultura do milho na região Centro-Oeste do Brasil e para o Estado de Minas Gerais. Revista Brasileira de Agrometeorologia, Passo Fundo, v. 9, n. 3, p. 527-535, 2001.

SCHAFFRATH, V. R. et al. Variabilidade e correlação espacial de propriedades físicas de solo sob plantio direto e preparo convencional. Revista Brasileira de Ciência do Solo, Viçosa, v. 32, n. 4, p. 1369-1377, 2008.

SILVA, M. B.; BELTRÃO, N. E. M. Níveis populacionais e configurações de semeadura na cultura do amendoim, em regime de sequeiro na mesorregião do agreste da Borborema do Estado da Paraíba. Revista de Oleaginosas e Fibrosas, Campina Grande, v. 4, n. 1, p. 23-34, 2000.

SOUZA FILHO, J. L. M.; GOMES, S. Avaliação e desempenho de equações de estimativa do armazenamento de água no solo em um balanço hídrico climatológico decendial irrigacionista. Revista Ciência Agronômica, Fortaleza, v. 29, n. 4, p. 433-443, 2007.

XAVIER, A. C.; CECÍllO, R. A.; LIMA, J. S. de S. Módulos em matlab para interpolação espacial pelo método de krigagem ordinária e do inverso da distância. Revista Brasileira de Cartografia, Rio de Janeiro, v. 62, n. 1, p. 67-76, 2010. 